\title{
Antik Dönem Tıbbının Müntahab-ı Şifâda Tezahürü
}

\author{
Babür Mehmet AKARSU* \\ Fuat YÖNDEMLI \\ Seda AKARSU
}

\begin{abstract}
ÖZ
Hacı Paşa ismiyle de bilinen Hekim Celâlüddin Hızır'ın yazmış olduğu Müntahab-ı Şifâ adlı eser, Anadolu'da yazılmış ilk Türkçe tıp kitapları arasında yer almaktadır. Yaptı̆̆g çalışmalar ve yazdığı kitaplarla tıp bilimine büyük katkıları olan Hacı Paşa, Müntahab-ı Şifầyı, Arapça yazdığı Şifâül-Eskâm ve Devâül-Âlâm isimli tıp kitabını özetleyip, Türkçe'ye çevirerek oluşturmuştur. Müntahab-1 Şifầnın temelini teşkil eden Şifâül-Eskâm ve Devâül-Âlâm’ın, Hacı Paşa'nın bizzat kendi el yazısıyla yazdığı nüshası Topkapı Sarayı Müzesi Kütüphanesi’ndedir. Hacı Paşa bu eseri Aydınoğlu İsâ Bey adına Arapça olarak 14. yüzyılda kaleme almıştır. Şifâül-Eskâm ve Devâül-Âlâm temelde; teorik ve pratik tıp bilgileri, yiyecekler- içecekler ve ilaçlar, organların ve tüm vücudun hastalıkları ile tedavileri olmak üzere dört bölümden meydana gelmiştir. Hacı Paşa, Müntahab-ı Şifầyı takdim ederken, bu kitabı hekimin bulunmadığı bir yerde halkın da kitabı anlayıp, gerekli tedavilere kısmen de olsa başvurabilmeleri için sade bir şekilde hazırladığını belirtmiştir. Bunun için de kitapta karmaşık tıbbi anlatımlardan

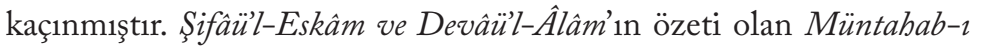
Şifâ adlı eser üç ana bölümden (bahs) oluşmaktadır. Birinci bölüm; tıp bilgileri ve tıbbın amacının detaylı bir şekilde anlatıldı̆̆ı iki alt bölüme
\end{abstract}

\footnotetext{
* Dr. Öğr. Üyesi, Sinop Üniversitesi, Fen-Edebiyat Fakültesi, Arkeoloji Bölümü, Sinop/Türkiye E-posta: baburakarsu@sinop.edu.tr, ORCID: 0000-0003-0004-8963,DOI: 10.32704/erdem.749007 Makale Gönderim Tarihi: 20.11.2019* Makale Kabul Tarihi: 15.04.2020 * (Araştırma Mk.)

** Emekli, Prof. Dr., Necmettin Erbakan Üniversitesi Tıp Fakültesi Konya/Türkiye E-posta: fyondemlikbb@yahoo.com, ORCID: 0000-0001-9051-1741

Arkeolog, E-posta: sedaakarsu3@gmail.com, ORCID: 0000-0003-0319-37601
} 
(teorik ve pratik kısımları) ayrılmıştır. İkinci bölümde; tedavi amaçlı kullanılacak gıdalar, şerbetler ve ilaçlar listelenmiştir. Üçüncü ve son bölümde; hastalık sebepleri, belirtileri ve bu hastalıkların tedavisinde kullanılacak ilaçların terkipleri detaylıca açıklanmıştır. Müntahab-ı Şifâ vasıtasıyla, temelinde Antik Dönem düşünürlerinin prima materialarının yer aldığı ve zamanla geliştirilerek Antik Dönem tıbbının hastalık, iyileşme ve sağllk halinin dengede olma ölçütü olan Humoral Patoloji Teorisi'nin Hacı Paşa tarafından da baz alındığı görülmektedir. Hacı Paşa, ekseriyetle kendi tıbbi uygulamalarını aktararak yazdığ 1 Müntahab-ı Şifầyı oluştururken, yararlandığı Antik Dönem’in batılı ve Ortaçağ'ın doğulu seçkin hekim ve bilginlerinin isimlerini bilhassa açılamıştır. Aristoteles, Hippokrates, Ephesoslu Rufus, Galenos, bu eserde alıntı yaptığını belirttiğgi Antik Dönem batı tıbbının ünlü hekimlerinden bazılarıdır. Hacı Paşa, bu hekim ve bilginlerden birtakım hastalıkların tedavi yöntemleriyle ilgili alıntılar yaptığını ve bu özel tedavi metotlarını önermeden önce hastalar üzerinde uyguladığını üstünde durarak açıklamıştır. Hacı Paşa, bu tedavi yöntemlerini aktarırken de öncelikli olarak formülünü hangi hekimden aldığını söylediği basit ve karmaşı ilaçların terkiplerini, bunların hangi hastalıkların tedavisinde ve nasıl tatbik edileceklerini detaylı olarak belirtmiştir. Bu çalışmada, Müntahâb-ı Şifẩnın içeriğindeki teorik ve pratik bilgiler, Antik Dönem batı tıbbının bilgileriyle karşılaştırılarak dönemin tıp literatürü incelenmeye çalı̧̧lacaktır.

Anahtar Kelimeler: Prima Materia, Şifâül-Eskâm ve Devâül-Âlâm, Aristoteles, Hamam, Nekahet Dönemi. 


\title{
The Manifestation of Medicine of Ancient Period in Müntabab-ı Şifâ
}

\begin{abstract}
The work with the name of Müntahab-ı Şifâ written by Physician Celâlüddin Hızır who is known as Hacı Paşa is regarded as one of the first Turkish medicine books written in Anatolia. Hacı Paşa who provided giant contributions to the science of medicine through his studies and the books he wrote, formed Müntahab-ı Şifâ by summarizing then translating his book called Şifâül-Eskâm ve DevâülÂlâm from Arabic to Turkish. The manuscript of Şifâül-Eskâm ve Devâül-Âlâm which forms the basis of the Müntahab-1 Şifâ, is in the Topkapı Palace Museum Library and it is written by Hacı Paşa himself. Hacı Paşa wrote this work in Arabic on behalf of Aydınoğlu İsâ Bey in the 14th century. Şifâül-Eskâm ve Devâül-Âlâm is basically consists of four chapters; theoretical and practical medical knowledge, food-drinks and medicines, diseases and treatments of organs and the whole body. While presenting Müntahab-ı Şifâ, Hacı Paşa stated that he had prepared this book for a place where the physician was not available, so that the public also could understand the book and apply it to the necessary treatments partially. For this, he avoided complicated medical explanations in the book. The work with the name of Müntahab-ı Şifâ, which is the summary of Şifâül-Eskâm ve Devâül-Âlâm, consists of three main chapters (topics). First chapter; it is divided into two sub-sections (theoretical and practical parts), in which medical information and the purpose of medicine are described in detail. In the second chapter; the foods, caudles and medicines to be used for therapeutic purposes are listed. In the third and last chapter; disease causes, symptoms and the compositions of the drugs to be used in the treatment of these diseases are explained in detail. Through the work called Müntahab-ı Şifâ it is seen that, the humoral pathology theory which based on the prima materias of antique thinkers then gradually developed and became the criterion of disease, healing and equilibrium of health status of the medicine of antiquity is also based by Hacı Paşa. While forming Müntabab-ı Şifâ which he wrote largely through narrating his own medical applications, Hacı Paşa especially explained the exclusive names of the physicians and the scholars of both from Antique Age of the West and Middle Age of the East. Aristoteles, Hippokrates, Rufus of Ephesos, Galenos are some of the famous physicians of the ancient western medicine, which he cited in this work. Hacı Paşa notedly stated that he cited some of the methods of treating of some diseases from these physicians and scholars and he applied those specific treatment methods on the patients before
\end{abstract}


he suggested them. While transferring these treatment methods, Hacı Paşa firstly stated in detail which physician he got his formula from, the compositions of the simple and complex medicines he said, the treatment of these diseases and how they should be applied. In this article, the theoretical and practical knowledge in the content of Müntahab-ı Şifâ will be compared with the knowledge of the western medicine of antiquity, so the medical literature of the period will be examined.

Keywords: Prima Materia, Şifâül-Eskâm ve Devâül-Âlâm, Aristoteles, Bath, Period of Recovery. 


\section{Giriş}

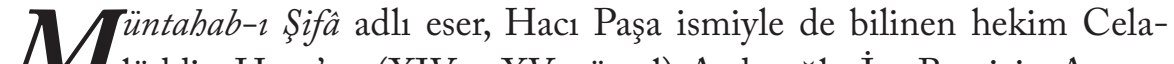
1 lüddin Hızır'ın, (XIV. - XV. yüzyıl) Aydınoğlu İsa Bey için Arapça yazdığı Şifâül-Eskâm ve Devâül-Âlâm adlı tıp kitabından seçtiği bölümleri Türkçeye çevirerek meydana getirdiği tıp kitabıdır (Kaya 2009: 120). Eserin çok sayıda nüshası vardır. Çalı̧̧ma konumuz olan Müntabab-ı Şifâ isimli kitap, Malatya İ1 Halk Kütüphanesi'ndeki 1196/2 numarada kayıtlı olan nüsha ve Paris Bibliothègue Nationale'deki A. F. 170 numarada kayıtlı nüshalara dayanılarak hazırlanmıştır (Önler 1985: 90).

\section{Antik Dönem Tıp Teorileri}

Sicilyalı Filozof Empedokles'in (MÖ 492-432) kurduğu ve Hippokrates'in (MÖ460-370) uygulamalarıyla Antik Dönem tıbbına yön veren Dört Unsur Teorisi'nde; birbirine zıt ikişer fiziksel özelliğe sahip dört ana eleman, dört humora karşılık gelmekteydi. Buna göre; kan, sıcak-nemli olan havaya; balgam, soğuk-nemli olan suya; sarı safra, sıcak-kuru olan ateşe; kara safra, soğuk-kuru olan toprağa karşılık gelir (Thomson 1998: 367; Eliaçık 2010: 130; Bayat 2016: 108, 122-123).

Orta Çağ Doğu tıbbında ablat-ı erbaa adıyla bilinen, Antik Dönem batı tıbbının temel kuramı olan Humoral Patoloji Teorisi'nin ve dört unsurunun Doğu tıbbında kabul gördüğü şekliyle Hacı Paşa tarafindan da kan, balgam, safra (sarı safra) ve sevda (kara safra) olarak belirlendiği görülmektedir.

Hacı Paşa'nın aktardığına göre: Gıdalar midede hazım olduklarında, kaynamış arpa suyuna benzeyen bir sıvıya dönüşürler. Buna keylus (kilus/chylus) denir. Keylus mideden ciğere ulaşarak tekrar hazım olup, dört humor (hilt) yani kan, safra, balgam ve sevdanın oluşumunu gerçekleştirir. Bu şekilde oluşan dört humor damarlara gelerek yeniden hazım olur ve buradan organlara dağılır. İlk önce kan oluşur. Kanın mizacı sıcak ve nemlidir. Sağlıklı kan kızıl renkli, kötü kokmayan, ne fazla sıvı ne de fazla yoğun kıvamda olmayan kandır. Kanın oluşumu et, yarı pişmiş yumurta gibi iyi gıdalardan sağlanır. Safranın mizacı sıcak ve kurudur. Safra, sıcak, tatlı ve yağlı gidalardan oluşur. Safra fazlalığında hazım ve iştah zayıf olup, kuvvet zayıflı̆ı meydana gelir. Balgamın mizacı; soğuk ve nemlidir. Balık ve yoğurt gibi soğuk ve nemli gidalardan meydana gelir. Sevdanın mizacı; soğuk ve kurudur. Sevda; sarımsak, peynir ve kuru balık gibi katı ve sicak gidalardan hasil olur. Herhangi bir humor yanarsa sevdaya dönüşür (Hacı Paşa 1990: 9, M2a). 
Galenos, Erasistratos'un sindirim teorisini benimseyerek mide ve bağırsakta sindirilen besinlerin bağırsak sıvısı (kilüs/ chyle) şeklinde bağırsak zarı damarlarına geçtiğini aktarmışır. Bağırsak zarı damarlarından geçen kilüs karaciğere ulaşarak, burada kana dönüşür. Karaciğerden vena cava ile kalbin sağ karıncığına gelen kan buradan da tüm vücuda dağılır. Gıdanın, oranları uygun olmayıp vücut tarafından tüketilemeyen bölümü dalak tarafından absorbe edilerek, kara safraya çevrilir (Singer 1928: 58; Furley ve Wilkie 1984: 35; Śródka 2003: 10).

Humoral Patoloji Teorisi kapsamında vücuttaki humorların dengesinin bozulması, bu sıvılardan bazılarının belli şartlar altında birbirine dönüşmelerinden (kara safra hariç), ya da mevsim ve beslenme gibi dış etkenlerden kaynaklanabilir (Hippocrates 1978: 161). Her bir mevsim ayrı ayrı dört unsurun özelliklerine sahip olduğundan mizaçların farklılaşmasına yol açarlar. Kan, sıcak ve nemli ilkbahar; sarı safra, sıcak ve kuru yaz; kara safra, soğuk ve kuru sonbahar; balgam, soğuk ve nemli kışa karş1lık gelir. Hippokrates, mevsimleri kuraklık, yağış ve rüzgar durumuna göre detaylı olarak incelemiş ve bu şartlar halinde ortaya çıkabilecek hastalıkları sıralamıştır. Örneğin; kış aylarında havanın 1lık, yağışlı ve güney rüzgarlarının hâkim olduğu şekilde; ilkbaharın kurak ve kuzey rüzgarlarının hâkim olduğu biçimde geçmesi durumunda ilkbaharda hamile olan kadınların en ufak bir sebepten ötürü bile çocuklarını düşürebileceklerini söyler. Yine bu şartlar altında ilkbaharda doğumun gerçekleşmesi halinde bebeğin ölebileceğini ya da sağliksız bir yaşam süreceğinin altını çizerek bunun dışında kuru göz hastalıkları, dizanteri ve yaşlıların ölümüne yol açabilecek nezle vakalarının olabileceğini belirtir. Yazın kurak geçmesi ve kuzey rüzgarlarının hâkim olmasi; sonbaharın yağışlı geçmesi ve güney rüzgarlarının hâkim olması durumunda kışın baş ağrısı, öksürük, ses kısıklığı ve bazı durumlarda verem vakalarının ortaya çıktığını aktarır. Sonbaharın yağışsız ve kuzey rüzgarı hâkim bir şekilde geçmesi sonucunda, kuru göz hastalığı, soğuk algınlığı ve nadirde olsa melankolik vakaların ortaya çıktığını söyler (Foster 1994: 6; Hippokrates 2016: 18-19, 3.12-3.14).

Galenos, iklimin ve o mevsimde yenen gidaların etkisiyle ilkbaharda kanın, yazın sarı safranın, sonbaharda kara safranın, kışın balgamın oranın artacağını savunmuştur. S1cak yiyeceklerin sarı safrayı, soğuk yiyeceklerin balgamı meydana getirdiğini iletmiştir. Bu bağlamda Galenos'un belirttiğine göre, soğuk hastalıklara balgam, sıcak hastalıklara sarı safra neden olur (Galen 1916: viii, 117-118; Bayat 2016: 122, 124). 
Hacı Paşa'nın aktardığı üzere ilkbaharda kan artar ve buna bağlı olarak ç1banlar çıkar, şişlikler meydana gelir, boğaz ağrısı olur. Yaz mevsiminde safra artar ve bu doğrultuda kuvvet zayıllı̆̆ zayıflığ 1 ile sıcak hastalıklar meydana gelir. Kışın balgam artar ve nezle, öksürük, bel ağrısı ortaya çıkar. Sonbahar da sevda fazlalığı oluşur, yel, dalak büyümesi gibi hastalıklar görülür (Hacı Paşa 1990: 9, M2a-M2b).

\section{Teşhis ve Tedavi Yöntemleri}

Nabzın tanımına Hippokrates’in çalışmalarında rastlanılmıştır. Ancak Hippokrates yüksek ateş, letarji gibi bazı hastalık durumlarını açıklarken arteriyel nabzın özelliklerini tanımlamı̧̧ır (Hippocrates 1849: 258, 351).

Koslu hekim Praksagoras (MÖ 340), arterler ve venlerde hava dolaştığını iddia etmesine rağmen, nabız atışının venlerde değil sadece arterlerde gerçekleştiğini keşfetmiştir (Ghasemzadeh ve Zafari 2011: 2; Lewis 2017:8).

Praksagoras'ın öğrencisi olan Khalkedonlu Hekim Herophilos (MÖ 335280), hocasının aksine damarların içinde hava değil, kan olduğunu gözlemlemiş ve kalp atışı ile nabız arasındaki bağlantıyı tespit etmiştir. Herophilos, nabızda iki dinlenme aralığını tanı yöntemi olarak kullanmıştır. Nabız ritmini ölçerken Clepsydra (su hırsızı) yani su saati kullanan ilk hekimdir. Nabzın büyüklüğünü, ritmini ve kuvvetini kaydetmiştir. Nabzın temel olgusunun ritim olduğunu vurgulayan Herophilos, nabız atışlarını emekleyen (karınca gibi ă̆ır hareket eden) ve sıçrayan (keçi gibi sıçrayan) atışlar gibi benzetmeler yaparak tanımlamıştır. Keçi sıçrayışına benzettiğ i nabız tanısında; ilk vuruşu takip eden ikinci vuruş daha güçlüdür (Herophilus 1989: 282, 285-286, 338; Pearce 2013: 292-293).

Archigenes (1.-2. yüzy1l), dikrotik nabzı ilk tanımlayan hekimdir. Boyut, hız, sıklık, sertlik, dolgunluk, düzenlilik (ya da düzensizlik), düzlük (eğiklik) ve ritim olmak üzere nabzın 8 niteliğini belirlemiştir (Prioreschi 2001: 172: Ghasemzadeh ve Zafari 2011: 3).

Roma İmparatoru Marcus Aurelius'un (161-180) başhekimi olan Bergama1. Hekim Claudios Galenos (129-200), artelerin eylemi olarak tanımlad1ğ1 nabzın farklı varyasyonlarını sınıflandırarak, nabız ile hastalık arasındaki ilişkiyi kurmuştur. Nabız tipinden hastalığın mizacını saptamıştır. Testere kenarl, dalgal, solucana benzeyen gibi tasvirlerle arteriyel nabzın birçok tipini tanımlamıştır. Galenos nabzın özelliklerinin; sindirim bozukluğu, belirli organların işlev bozukluğu veya psişik hastalıklar gibi birtakım rahatsızlıklara 
bağlı olarak değişebileceğini ileri sürmüştür. Nabzın, ölçü, hız ve sıklık kriterlerini baz alarak 27 niteliğini açılamıştır. Bir kadının sevgilisinin adını duymasının nabzını hızlandırmı̧̧ olduğunu tespit etmesi en önemli gözlemidir (Üstün 2004: 455; Mattern 2008: 151).

Nabız sayma, Hacı Paşa'nın tanı yöntemleri arasında yer almaktadır. Nabzın ritmine göre vücutta humor fazlalıklarından kaynaklanan rahatsızları teşhis etmiştir. Örneğin: Hasta sinirlenmemişse, korkmamışsa, çok sevinmemişse, aç değilse, çok yemek yemediyse, çok hareket etmediyse ve bu durumlara rağmen nabzı çok hızlı atıyorsa, sıcaklık fazlalığı vardır. Nabız, enli ve dolu olup, yavaş yavaş atıyorsa soğuk-nemli mizaçlı balgam fazlalığının göstergesidir. Damarlar ince ve çekilmiş gibiyse kuruluğa, damarlar sıcak olursa sıcaklı̆̆a, damarlar soğuk olursa neme işaret eder. Nabız yumuşaksa ve hızlıysa kan fazlalığının; hızlı ve gergin şekilde atıyorsa safra fazlalığının (sarı safra) delilidir. Geç ve yumuşak atan nabız balgam fazlalığının, yavaş ve gergin nabız sevda fazlalığının (melankoli) göstergesidir (Hacı Paşa 1990: 10-11, M3a).

Antik Dönem hekimlerinin kullandığ 1 teşhis yöntemleri arasında yer alan nabız ve mizaç ilişkisi dahilinde; zayıf nabız balgam fazlalı̆̆ının, sık sık atan ve kuvvetli nabız kan fazlalığının, kuvvetli ve dolgun nabız safra fazlalığının, yavaş ve dolgun nabız ise kara safra fazlalığının (melankoli) emaresidir (Prichard 1847: 350).

Hippokrates, idrarın humorların filtre edilmiş hali olduğunu ileri sürmüş ve hastalığın teşhisi aşamasında idrar muayenesinden yararlanmıştır. İdrarın renginin, tortusunun, yoğunluğunun ve kokusunun incelenmesini esas alan idrar muayenesinden yola çıkan Hippokrates, idrarda oluşan değişimlerden hastalıkları teşhis etmiştir.

İdrar muayenesinde çeşitli sınıflandırmalar yapan Hippokrates, ilk başlarda ince olan idrarda safralı çökeltiler meydana gelirse, aniden gelişen hastalıkların ortaya çıkacağını ileri sürmüştür. Köpüklü idrar, uzun süreli seyreden böbrek hastalıklarının olacağının işareti olduğunu belirten Hippokrates özellikle idrardaki köpüğün yağlı ve kümelenmiş olduğunda aniden oluşan böbrek hastalıkları baş göstereceğini aktarmıştır (Hippokrates 2016: 49, 7.32-7.35; Kouba ve Wallen vd. 2007: 50).

Hippokrates'e göre menenjit hastalarında olduğu gibi idrarın şeffaf ve renksiz olması iyiye işaret değildir. İdrarda kan veya iltihabın mevcudiyetinin böbrek ya da mesanede yaraların var olduğunu gösterdiğini aktarmıştır. İdrarda aniden kan gözükmesi böbreklerdeki küçük damarlardan birinin kopmuş 
olduğuna, koyu idrarla birlikte kıl formlu et parçacıklarının mevcut olması böbreklerden salgılanan ifrazatın varlığına delalet eder (Hippokrates 2016: 30-31, 49, 4.72, 4.75, 4. 76, 4.78, 7.33, 7.35). İdrarda kumlu çökeltinin olması mesanede taş olduğunun, kan pihtısı ile idrar güçlüğünün bir arada görülmesi mesane bölgesindeki organların hastalandığının işaretidir. İdrarda kan, iltihap ve pullar ile beraber kötü kokunun olması, mesanede yaraların meydana geldiğinin, koyu idrar ile birlikte kepeğe benzeyen parçacıkların var olması mesanede kabuklanmanın olduğunun göstergesidir (Hippokrates 2016: 3031, 4.76, 4.77, $4.79-4.81$ ).

Aristoteles (MÖ 384 - 322), idrarın mesanede üretildiğini ileri sürmüştür. Böbreklerin kandaki fazla suyu süzdüğünü tespit eden Aristoteles'in belirttiği üzere suyun kandan ayrılması için belirli bir kaynama süresi gerekmektedir (Marketos ve Eftychiadis vd. 1993: 290; Cooper 2004: 134).

Kapadokyalı Aretaeus (120-200) diyabeti, idrar içinde uzuvların ve bedenin erimesi olarak tanımlamıştır. Diyabet hastalığını da, hastanın sürekli su içerek aşırı derecede idrara çıkmasından dolayı yani aradan geçmek, akıp gitmek

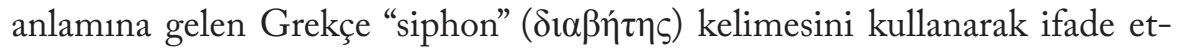
miştir (Aretaeus 1856: 338-339).

Galenos, idrarın rengi, tortusu ve yoğunluğuna bakarak idrardan humor fazlalıklarını tespit etmiştir. İdrarın böbreklerde meydana geldiğini saptamış, böbrek ve mesane kaynaklı kanamaları gözlemleriyle ayırabilmiş, kanın böbreklerde temizlendiğini tespit etmiştir (Marketos ve Eftychiadis vd. 1993: 290; Graham 2009: 52). Galenos, çok fazla idrara çıkılmasından dolayı şeker hastalığını "idrar diyaresi” olarak adlandırmıştır (Rosenfeld 1996: 156).

Hacı Paşa'ya göre, idrar tahlili yapılmadan bir gün önce safran ve tere gibi idrarı boyayacak maddeler yenilip içilmemeli, çok aç, susuz, uykusuz kalınmamalı ve sinirlenilmemelidir. İdrar yapıldıktan üç saat sonra tahlil edilmelidir. Portakal kabuğu rengi, çok yoğun olmayan, dibinde, ortasında yahut çevresinde tortusu olan ve keskin kokusu olmayan idrar, vücuttaki humorların piştiğini gösterir. İdrarın renginin kızıl ve bulanık olması kan fazlalı̆̆ına işaret etmektedir. İdrarın kara, az yoğun ve berrak yapıda olması sevda fazlalığının belirtisidir. İdrarın bozumsu (boza çalar renkli) ve bulanık olması, balgam fazlalığına delalet eder. İdrarın çok ve galiz köpüklü olması da balgam ve yel fazlalığının belirtisidir. Sarı renkli, berrak ve yoğunluğu az olan idrar, safra fazlalığının göstergesidir. İdrarın renginin kızıl, sarı veya kara olması vücutta hararetin hâkim olduğuna, beyaza yakın açık sarı renkli idrar ise vücutta soğukluğun (bürudet) hâkim olduğuna işaret eder (Hacı Paşa 1990: 11, M3b). 
Hacı Paşa, yeraltı sularının balgamı boşalttığını, uyuz, kaşıntı, titreme ve kötürümlüğe iyi geldiğini ancak uzun süreli kullanımı sonrası baş ağrıttığını söylemiştir (Hacı Paşa 1990: 15, M7a).

Galenos, termal su kürlerini çeşitli yaralanmalar başta olmak üzere eklem ve idrar yolu hastalıkları için reçete etmiştir. Padua ve Aquae Albulae gibi bazı termal kaynakların sularının bir takım hastalıklar açısından tedavi edici olduğunu vurgulayan Galenos, bu kaynakların sularının fazla kullanımlarının vücuttaki humor dengesini bozucu zararları olduğunu da belirtmiştir. Bu zararların başında özellikle vücuttaki nemlilik dengesini bozan hastalıklar gelmektedir (Jackson 1990: 11; Nutton 2013: 248).

Ephesoslu Hekim Rufus (MS 1.-2. yüzyıl), masaj ve ilaç kürlerine ek olarak özellikle iç hastalıklarının tedavisinde termal hamam kürlerini reçete etmiştir. Böbrek sklerozuna (nefroskleroz) bağlı olarak gelişen ağrı seyrinde termal hamam reçete etmesi bu duruma örnek olarak gösterilebilir (Black 1980: 514).

Kapadokyalı hekim Aretaeus (MS 2. yüzy1l), cüzzam ve melankolinin rehabilitasyonunda kaplıcalardan yararlanmanın mümkün olduğunu bildirmiştir (Luke ve Forbes 1913: 1; Rufus 2008: 63). Romalı mimar ve yazar Marcus Vitruvius Pollio (MÖ 80-15), termal suları içerdikleri erimiş mineral maddelerine bağlı olarak sertlik derecelerine ve buna bağlı olarak tedavi edici özelliklerine göre sınıflandırmıştır. Buna göre; kükürt, şap, katran, bitum (bitumen) içeren, alkali maddeli ve asitli termal kaynaklar; kas hastalıklarını, sinir hastalıklarını, felç ve benzeri hastalıklar ile kötü humorları tedavi edici, müshil etkisine ve mesane taşlarını eritici özelliğe sahiptirler (Vitruvius 1826: 238-239; Jackson 1999: 160).

G. Plinius Secundus (MS 23-79), sıcak su kaynaklarının yaraları iyileştirdiğini, kadınlardaki kısırlığı tedavi edici nitelikte olduğunu ayrıca bu kaynaklardan göz hastalıklarının sağaltımında, eklem ve sinir hastalıklarının terapisinde yararlanılabileceğini aktarmıştır (Paulus Aegineta 1844: 72; Plinius 1847-1848: V. XVI).

Hacı Paşaya göre hamam; pislikleri vücuttan atar, humorları pişirir, uyuz ve kaşıntıyı alır, sivilce ve çıbanlara fayda eder, uyku getirir ve yorgunluğu alır. Ancak hamam vücudunda şiş, cerahat ve kırık olan hastalar ile hazımsızlık çeken hastalara zararlıdır. Hamamda çok oturmak çarpıntıya sebep olur, iştahı azaltır. Kış gününde hamama girenlerin çıkışta soğuktan korunmaları için kalın giysiler giyinmelerini öğütler. Hamama girecek olanlar ne aç ne de tok olmalıdırlar yani yiyeceklerin hazmı gerçekleştikten sonra hamama girilmeli- 
dir. Şişman kişiler hamamda terleyene kadar oturmalı, zayıf kişiler hamamda az oturmalı ve 1lık suyla uzun süre yıkanmalıdırlar. Nekahet dönemindeki kişiler 1 lık hamamda yıkanmalıdırlar. Yine de bu hastalar hamamda çok oturmamalı, çok terlememelidir (Hacı Paşa 1990: 14, 16, M6b, M8b).

Hippokrates'in belirttiği üzere; zayıflar şişmanlardan daha fazla yıkanmalıdırlar. Sıcak banyo boş mide ile yapılırsa zayıflatıcı etkiye sahiptir. Sıcak banyo yemekten sonra yapılırsa; kişi hem ısınır hem de vücudu yumuşar. Soğuk banyo vücudu kurutur ve zayıflatır. Banyo, kapalı bir mekanda, aç karnına, buhar olmaksızın ve bol su ile yapılmalıdır. Yıkanma, yüksek ateş, mide bulantısı, kusma ve burun kanaması durumlarında önerilmemiştir (Phillips 1973: 77-84; Yegül 2006: 38).

Bithynialı Hekim Asklepiades (MÖ 124-40) hamamın, bazı hastalıkların tedavisi için kullanılmasının doğru bir yöntem olduğunu ve banyo uygulamasına sınır getirilmemesi gerektiğini belirtmiştir. Celsus, tendon rahatsızlıklarının tedavi edilmesi veya humor fazlalıklarının düzeltilmesi için sıcak su banyosu önermiştir (Jackson 1999: 43).

Kadın hastalıkları ve doğum uzmanı Ephesoslu Soranus'a (MS 1.-2. yüzyıl) göre; hamile kadınlar hamileliklerinin ilk dönemlerinde sıcak su banyosu yapmaktan kaçınmalıdırlar. Çünkü ilk dönemlerde hamilelerin sıcak su banyosu yapmaları düşük ile sonuçlanabilir. Hamileliğin ilerleyen dönemlerinde sıcak su rahat bir doğum yapılabilmesi açısından faydalıdır (Soranus 1956: I, 46; I, 54-56; III, 10-16; III, 28; III, 32; III, 38).

Hacı Paşa da çocuk düşürmekten korkan hamile kadınların, hamama girmekten çekinmeleri gerektiğini vurgular. Ancak doğumda zorluk yaşayan kadınların da doğum sancıları başladığında hamama götürülmesini, gövdelerine sıcak suyun çok dökülmesini ve mümkünse sıcak su içine oturtulmalarını tavsiye etmiştir (Hacı Paşa 1990: 17, M9a).

Galenos, hem sağlıklı kalmak hem de sağlığa kavuşmak için Roma hamamlarının kuruluş şemalarıyla uyumlu banyo yöntemi hazırlamıştır. Terapiye yönelik banyo yöntemi sıralaması, rahatsızlı̆̆ın türüne göre de değişmektedir. Buharın vücudun kuruyan kısımlarını nemlendirdiğini söyleyen Galenos, soğuk su banyosunun vücuttaki gözeneklerin kapanmasını sağladığını ve vücut direncini arttırdığını açılar. Yağlanmak, derideki gözenekleri kapatıp, fazla havanın deriye geçmesini engelleyerek cildi sert ve zararlı rüzgarların sebep olduğu kuruluktan korur. Terlemenin arkasından son bir masaj ve yağlama yapilırsa, ter vücudu temizler (Yegül 2006: 39; Mattern 2008: 143). 
Antik Dönem tıbbi öğretisine göre soğuk suyu içmek, dökünmek, vücudun hastalıklı bölgelerini içine sokup çıkartmak ve yıkanmak şeklinde olan tüm uygulamalar, hem sağlıklı kalmanın hem de tedavinin bir parçasını oluşturmuştur.

Pythagoras (MÖ 570-495) ve Hippokrates, pek çok hastalı̆̆ın tedavisinde ya da sağlık halinin korunabilmesi için soğuk su banyosunu önermişlerdir. Pythagoras, talebelerine soğuk su banyosunun hem vücudu hem de zihni dinç tutacağını empoze etmiştir. Palestrada yapılan egzersizlerden sonra özellikle soğuk su banyosu yapılmasını tavsiye eden Hippokrates, soğuk su banyosu terapisine soğuk su ile ovma yöntemini getirmiştir (Claridge 1849: 41; Rhydding 1872: 762). Hippokrates, soğuk su afüzyonunun kas kramplarına, gut hastalığına bağlı olarak ortaya çıkan ayak şişmesi ve ağrı şikayetleri için uygulanması gerektiğini belirtmiştir (Shew 1849: 17).

Keoslu Hekim Erasistratos (MÖ 304-250), iç kanamayı kontrol etmek ve beynin güneşe maruz kaldıktan sonraki alevlenmesini önlemek için soğuk suya doymuş süngerler ile kompres (soğuk kompres) yapılmasını tavsiye etmiştir (Stillé 1874: 246). Tedavi için önerdiği soğuk su reçetelerinin fazlalığı nedeniyle Asklepiades "soğuk su veren" lakabıyla anılmıştır (Fagan 2002: 98). Antonius Musa, hekimi olduğu Roma imparatoru Augustus'un (MÖ 63-14) rahatsızlı̆̆1 olan karaciğer apsesinin tedavisi için uyguladığı karmaşık ilaç kürlerine soğuk su banyosu tedavisi ile son vermiştir (Jackson 1990: 3-4; Yegül 2006: 38).

Roma imparatoru Nero (37- 68) dönemi hekimlerinden Agathinus (50100), soğuk su banyosunun faydalarını başlıklar halinde açıklamıştır. Buna göre; soğuk su banyosu yapanların yaşlı dahi olsalar vücutlarının güçlü ve sıkı olacağını, yüzlerinin kanlı canlı bir renk alacağını, dinamik olacaklarını, iştahlarının açık ve sindirimlerinin hızlanacağını ve vücudun tüm doğal eylemlerini gerçekleştirebileceğini bildirmiştir. Ancak Agathinus, bebeklere soğuk su banyosunu kesinlikle yasaklamış, onlar için sıcak banyo (caldarium) önermiştir (Paulus Aegineta 1844: 70; Prioreschi 2001: 159).

Soğuk su banyosunun vücudu zinde tutacağını ifade eden Hacı Paşa, ishal, nezle, mide zayıflı̆̆1 ya da hazımsızlı̆̆1 olan kişilerin soğuk su banyosu yapmamaları gerektiğini aktarmıştır. Kışın soğuk su banyosu yapılmamasını belirtmiştir. Yazın da öğle vaktinde soğuk su ile banyo yapılmalı, olmazsa sabah veya akşama yakın saatler tercih edilmelidir (Hacı Paşa 1990: 14, M6b). Ayrıca Hacı Paşa, Galenos ve Oribasius'un da (MS 350) belirttiği gibi soğuk duşun, şiş ve iltihaba iyi geldiğini açıklamıştır (Jackson 1990: 2). 
Galenos, soğuk su banyosunun yaz ayı boyunca yapılmasını tavsiye etmiştir. Soğuk banyonun nasıl yapılması gerektiğini ayrıntılı şekilde anlatmıştır. Buna göre; banyoya girmeden önce havlularla vücut ovulmalı, sonra yağlanmalıdır. Ardından soğuk suya hemen dalınmalı, yavaş yavaş girilmemelidir. Sudan çıktıktan sonra deri ısınana kadar yağ ile vücuda masaj yapılmalıdır. Soğuk su havuzunun işlevini, vücuttaki gözeneklerin kapanmasını sağlamak, vücudun enerjisinin arttırmak ve bedenin güçlenmesini gerçekleştirmek olarak açıklamı̧̧tır (Paulus Aegineta 1844: 70; Yegül 2006: 39).

Hacı Paşa gıdalar tamamen hazım olduktan ve tekrar acıkmaya başladıktan sonra beden hareketlerinin yapılması gerektiğini belirtmiştir. Egzersizlerde, vücudu fazla yormadan ölçülü bir şekilde yapılmalıdır. Egzersizlerde ölçü; vücudun 1sınması, terlemeye başlamaktır. Egzersiz esnasında çok terlemek kuvveti azalttığından ve organları zayıflattığından zararlıdır. Hareketsizlik ise hazımsızlı̆ga sebep olur, iştahı azaltır, balgamı arttırır, humorları ham eder ve duyuları köreltir. Ölçülü bir şekilde vücuda masaj yapmanın (ovma), ölçülü bir biçimde egzersiz yapmaya benzer bir etkiye sahip olduğunu ifade etmiştir. Ovmanın vücudu güçlendirdiğini ve humor fazlalıklarını yok ettiğini söylemiştir (Hacı Paşa 1990: 13, M5b).

Hippokrates, egzersiz ile masajı tedavinin ve kaliteli yaşamın bir parçası olarak gördüğünü savunmuştur. Masajı nazik bir egzersiz biçimi olarak tanımlayan Hippokrates, masaj esnasında vücudun belli bölgelerine yapılan basıncın etkilerini sınıflandırmıştır (Jackson 1999: 28; Whorton 2000: 149). Özetle masajın uygulanma gücünün vücuda etkilerinin bir nevi sınıflandırmasını yapmıştır. Buna göre; güçlü bir şekilde yapilan masajın vücudu kuvvetlendireceğini, ölçülü bir şekilde yapılan masajın bedeni şişireceğini, kibar şekilde yapılan masajın vücudu gevşeteceğini, fazlaca yapılan masajın vücudu küçülteceğini aktarmıştır.

Asklepiades, sağlıklı olmak için beş temel sağlık prensibi belirlemiştir. Bunlar; diyet (gıdalardan ve şaraptan uzaklaşma), masaj, egzersiz (yürüme) ve şiddetli biçimde sallama sağlaması nedeniyle çeşitli araba gezintileridir (Jackson 1999: 26).

Celsus'un hastalıklara sebep olan humor fazlalıklarının vücuttan uzaklaştırılması amaciyla önerdiği yöntemler arasında egzersiz, masaj (ovma) ve sallama yer almaktadır. Yemekten önce egzersiz yapılması gerektiğini, terleyip yorulunca egzersizin bırakılmasını söylemiştir. Hazımsızlık sorunu olan kişi egzersiz yapmamal, işe gitmemeli ve yatmalı, dirençsiz kişiler ise pasif egzer- 
sizler yapmalıdırlar. Celsus'a has egzersizler arasında; yüksek sesle okumak, yürümek, koşmak ve top oynamak yer almaktadır. Ancak bu beden hareketleri gymnasiumlarda olduğu kadar ağır yapılmamalı, ölçülü olmalıdır (Jackson 1999: 26-28; Yegül 2006: 39).

İlk egzersiz fizyoloğu olan Galenos, ampirik çalışmalarla egzersizin etkilerini incelemiş, zinde bir vücuda sahip olabilmek için düzenli olarak egzersiz yapılmasını önermiştir. Sağlıklı yaşam reçetesinin önemli maddelerinden biri olan egzersizleri tüm yaş gruplarına tavsiye etmiştir. Ancak Galenos’a göre egzersizler dengeli ve bilinçli bir şekilde yapılmalıdır. Favori egzersizi olan top oyunlarının sağlıklı bir yaşam için önemini ayrıca vurgulamıştır (Jackson 1999: 28; Tipton 2003: 5, 8).

Humor fazlalıklarının kusma, müshil ve kan alma metotlarıyla vücuttan atılmasının esas alındığı boşaltım metodu, Antik Dönem’in etkin tedavi yöntemleri olmuşlardır.

Boşaltım metotlarından biri olan kusma, Hippokrates'e göre; doğal ya da yapay yollarla gerçekleştirilebilmektedir. Hippokrates, kusmanın hastanın sağllğına kavuşması yönünden yararlı olduğu kadar hastanın dayanabilirliği açısından da kolay bir terapi metodu olduğunu belirtir. Kusmasında mani bulunabileceğini ileri sürdüğü zayıf kişilerin dahi kolayca kusabiliyorsa kusturulması, kusmakta zorlanan şişman kişiler için alttan boşaltım yapılması gerektiğini aktarmıştır. Kış aylarından ziyade yaz ayları kusma yoluyla boşaltım için uygun mevsimlerdir. Doğal veya suni yoldan yapılacak olan kusmayı engellemenin sağlığı bozacağını da bilhassa belirtmiştir (Hippokrates 2016: 5, 23-24, 1.2, 4.2- 4.7).

Celsus, gut hastalığının tedavisi için kan aldırma, idrar söktürücü ilaçların kullanımı, sıcak ve soğuk pansuman ile birlikte kusma yönteminin uygulanması gerektiğini söylemiştir. Kusma yöntemi için ilaç kullanımını dahi önermiştir (Jackson 1999: 28; 178).

Hacı Paşa da kusmanın sağlıklı bir terapi yöntemi olduğunu aktarmıştır. Boynu uzun ve ince, göğsü daracık, boğazında şiş, midesi, gözü, tırnağ güçsüz, hamile kadın veya acıyla kusan kişilerin kusmaması gerektiğini belirtmiştir. Kusmaya uygun olmayacak hasta tiplerini açıklamasına rağmen gerektiği durumlarda bu yöntemin o kişilere dahi derhal uygulanması gerektiğini tembihlemiştir. Kusmanın durdurulmasının ise sağllğ̣1 ciddi şekilde bozacağını ifade etmiştir (Hacı Paşa 1990: 14, 21, M6a, M13a). 
Hippokrates, kan almanın göz ağrılarına, sırttan dirseklere kadar oluşan yırtılmalara ve idrar yapma güçlüğüne iyi geldiğini aktarır. İdrar yapma güçlüğünün iyileştirilmesi için içteki damarlar açılmalıdır. Hippokrates'e göre kan alma ve müshille boşaltım metotlarının kullanılacağı tedavide en uygun mevsim ilkbahardır (Hippokrates 2016: 43-44, 51, 6.22, 6.31-6.36, 6.47, 7.48, 7.53).

Celsus'a göre hasta güçlü bir bünyeye sahip ise yaşı ve hamile olma durumu kan alma yöntemi için risk teşkil etmez. Yüksek ateşi varsa, derisi kızarmışsa, kan damarları şişmişse özet olarak vücudun sağlığını bozan her durumda kan alınmalıdır. Hastalık vücudun genelini etkiliyorsa kan alma işlemi koldan yapılmalıdır. Hastalık vücutta belli bir bölgeyi etkiliyorsa şakaklardan, kollardan ve eklem yakınlarından kan alınmalıdır. Özellikle koldan kan alınırken kol veninden kan alınmasına özen gösterilmelidir. Yapılacak kesi, kol veni yerine kirişe denk gelirse kasılma, artere gelirse çok şiddetli kanama meydana gelir. Venin yarısı kesilmelidir. Kan koyu akarsa kan bozuk olup, rengi normale dönene kadar akıtılmalıdır. Kan, kırmızı ve berraksa sağlıklıdır (Jackson 1999: 66-67).

Hacı Paşa, soğuk mizaçılı kişilerin soğuk günlerde kan aldırmamalarını önermiştir. 14 yaşından büyük, 60 yaşından küçük olanlar kan aldırabilirler. Erkek çocuklardan iki yaşına kadar kan alınmaması gerektiğini özellikle belirtmiştir. Hamamda çok oturduktan sonra, çok hareket edip yorulduktan sonra ve sitma nöbeti esnasında kan alınmamalıdır. Kan aldırdıktan sonra tuzlu yiyecekler yenilir ise kişide uyuz ya da abraş hastalığ 1 (çilli, çopur) görülür. Kan, yaz aylarında sabah, kış aylarında kuşluk vakti alınmalıdır. Kan alınırken çıkan kan kara renkli ise kanın rengi açılana dek kan akıtılmalıdır. Hamileler, kan almaktan ve müshil içmekten sakınsınlar, çünkü bebeğin düşmesi ihtimali vardır (Hacı Paşa 1990: 17, 21-22, M8b, M13b).

Sağlık Tanrısı Asklepios'un Anadolulu oğlu Telesphoros'un nekahet tanrısı olmasından anlaşıldığı üzere, nekahet sağlıklı olma haline giden yolda önemli bir aşamadır. Antik Dönem hekimleri, banyoları nekahet dönemindeki kişiler için şart koşmuşlardır. Özelikle nekahet dönemi rehabilitasyonuna uygun olmayan plana sahip hastaneler için de kaplıcalar reçete edilmiştir.

Masaj ve sallama yöntemi nekahetteki kişilere tavsiye edilen egzersizler olmuşlardır. Asklepiades ateşli hastalıklardan sonraki nekahet dönemi boyunca masaj yapılmamasını, ödem ve leucophlegmasia'nın (ağrılı şiş bacak) iyileşme evresi için ise masajı tavsiye etmiştir. Kronik bir hastalık ve bilhassa ateş atağ 1 
atlatanlar için basit egzersizler öneren Celsus, nekahet döneminde olanlara aktif bir egzersiz olan ata binme yönteminin uygulanmasını tembihlemiştir. Celsus nekahetteki kişinin atlattığı hastalığının mizacına göre soğuk ve hafif yiyecekler önerir. Plinius ise nekahet diyetine taze incir reçete eder (Celsus 1831: III, XI; Jackson 1999: 43, 134, 178).

Hippokrates, nekahetteki kişinin iştahının yerinde olmasına rağmen bedeninde herhangi bir ilerleme kaydedilmemesinin iyiye işaret olmadığını belirtir. Nekahetteki kişinin yemek yemesine rağmen kuvvetlenmediği takdirde vücudunun ihtiyacı olandan fazla besin tükettiği şeklinde yorumlar. Nekahetteki kişi yemek yemediği halde güçlenemiyorsa vücudunun boşaltıma gereksinimi olduğunu aktarır. Hastanın ani ve şiddetli nöbetler geçirdiği esnada yiyecek miktarının aza indirilmesi görüşündedir. Hatta belirli aralıklarla şiddetlenen hastalıklarda oluşan şiddetli krizlerde de hastanın yemeğinin kısıtlanmasını uygun görür. Çünkü Hippokrates'e göre şiddetli krizler esnasında hastaya yiyecek vermek tehlikelidir. Erken dönem hekimleri, hastanın vücudu en iyi durumdayken yemek verilmesini önerirken; Asklepiades, hastanın ateşi düşünce yemek verilebileceğini belirtir. Laodikeialı Hekim Themison ise hatalı olarak iki saat ya da daha kısa süreli nekahet dönemi için yemek yenmesini öğütlemiştir (Hippokrates 2016: 7, 11, 14, 1.11, 2.8, 2.31; Crum 1932: 162).

Hacı Paşa, hastalıktan yeni kalkanların kanlarının az, gövdelerinin zayıf olduğunu bildirir. Dönemindeki bu kişiler, üç veya dört gün hastalıkları boyunca yaptıkları perhize devam etmeli, et yememelidir. Etsiz müzevvere denilen, muhtelif sebze ve meyveler kullanılarak pişirilen çorbaların nekahet dönemine uygun olduğunu vurgular. Ayrıca birden bire pilicin göğüs kısmının yedirilmeyerek, pilicin günlere göre parçalara ayrılarak aşama aşama hastaya yedirilmesini yani ilk gün pilicin boynunun, ikinci gün kanatlarının, üçüncü gün butlarının, en sonunda göğüs kısmının yedirilmesini öğütler. Fıstık, findık gibi kuruyemişlerden, ekşi yiyeceklerden, tatlı yiyeceklerden özellikle nişastalı olanlarından, helva ve pelte gibilerinden uzak durulmasını ve çok hareket edilmemesini şart koşar. Nekahetteki kişiler, aç ve susuz kalmadan gövdeyi kızdırır şeyleri yememeli ve içmemelidir ve bu kişilerin yiyeceklerini 1l1k ortamlarda yemesi ve hamamda 1lık su ile yıkanması gerekir. Ayrıca bu hastaların bulunduğu ortamlarında çok gürültülü olmaması şarttır. Hoş kokular koklamak ve güzel sözler işitmenin nekahet dönemindekiler için faydası vardır (Hacı Paşa 1990: 16, M8a-M8b). 


\section{Hacı Paşa'nın Antik Dönem Hekimlerinden Direkt Olarak Aldığı Tedavi Metotları}

Hacı Paşa, Hippokrates'in (Bukrat Hekim) doğuştan sağır kişinin tedavi edilemeyeceğini ancak kişi sonradan sağır olduysa düşükte olsa tedavi imkanının olduğunu söylediğini aktarır. Tedavi kapsamında hastanın erik şarabıyla ishal edilmesini, hastanın mizacı nermise (yumuşak) nar şerbeti içirilmesini veya hastanın kulağının elma şarabının sıcak buharına tutulmasını tembihler. Gül suyu, sandal (sandal ağacı) ve kafur otunun hastanın başına sürülmesinin, beyni güçlendireceğini belirtir. Bu süreç boyunca hasta sıcak ortamlarda bulunmamalı, sigencübin (sirkeli bal) adlı şurup ile gargara yapmalı, tatlı yiyecekler yememelidir. Bu hastaya ekşi yiyecekler verilmelidir. Galenos da bu hastalığın balgam ya da buhardan kaynaklanması durumunda ilacını: findık büyüklüğündeki kara harbakın (karacaot/kara çöpleme) dövülüp, balla eritilmesi ve bu karışımın kulağa konulması şeklinde formüle etmiştir. Hastalığın buhardan kaynaklı olması durumunda Galenos, bir miktar burenin (boraks) sirkede ezilip, kulağa konulmasını öğütler (Hacı Paşa 1990: 59, M51a).

Bununla birlikte Hacı Paşa, Galenos'un (Calinus Hekim), kulak iltihabında irin veya kan gelirse öncelikle sıcak bal şerbetinin kulağa damlatılmasını tembihlediğini söyler. Ardından anzarut (dikenli bir ağacın zamkı/ astragalus sarcocolla) ile birlikte iki kardaş kanı otu (calamus draco), günlük ve sabırlık otunun hafifçe dövülüp bir otlu karışım yapılmasını söyler. Sonrasında bala sokulmuş bir fitilin üzerine bu otlu karışımın bulanıp, hastanın kulağına konulmasını söyler. Bu kürün denendiğini ve hastanın ağrısını giderdiğini vurgular (Hacı Paşa 1990: 59, M51a). Hacı Paşa, Aristoteles’in (Arastatalis) bir kadının çocuk doğurmakta zorlandığında, bir parça çakmak taşını bir parça beze ve sonrada kendisine bağlarsa kolaylıkla doğuracağını söylediğini iletmiştir (Hacı Paşa 1990: 124, M110b).

Hacı Paşa, Ephesoslu Rufus'un (Rufes-i Hekim) çocuk hastalıkları için önerdiği tedavi metodunu da detaylıca aktarır. Ayıülüne, şakayıkın (paeonia officinalis) Yunanca'da favaniya, Türkçe'de baladı otu dendiğini açıklar. Sonra ayıgülünü tanımlar; çiriş otunun kökü gibi olduğunu fakat onun gibi uzun olmadığını ve çiçeğinin kırmızı gül gibi olduğunu söyler. Ayıgülünün kökünü hasta çocuğun boynuna takmalarını öğütler. Ayıülü kökünün hafifçe dövülüp, uçuklu çocuğun burnuna damlatılmasını ve uçuk hastalığının bu şekilde kaybolacağını aktarır (Hacı Paşa 1990: 180, M162a). 


\section{SONUÇ}

Hacı Paşa'nın Aristoteles, Hippokrates, Ephesoslu Rufus, İbn Sina, Hekim İshak, Medayini, Ebu Cüreyh, Muhammed bin Zekeriya, Hekim Huneyn gibi dönemlerinin önemli batılı ve doğulu hekimlerinden aldığ1 tedavi yöntemlerini uygulamış olduğu, gerektiğinde kendi geliştirdiği metotları da ekleyerek tavsiye ettiği görülmektedir. Bunlar arasında kadın hastalıkları ve doğum, kulak hastalıkları, çeşitli çocuk hastalıklarıyla ilgili yaptığı ve aktardığı alıntılar oldukça detaylıdır.

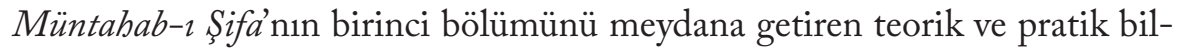
gilerin, Antik Dönem tıp bilgilerinin devamı niteliğinde olduğu net bir şekilde takip edilebilmektedir. Eserde tıbbın teorisi kapsamında bahsi geçen nabız ve idrar tahlili metotlarının dönemin tıp literatürünün belirlenmesi açısından önemli bir yeri vardır. Galenos’un geliştirdiği ve sonrasında sıkça kullanım gören vücut sıvilarından mizaç fazlalı̆̆ının tespiti ve buradan hareketle tedavi şeklinin belirlenmesi kuramının, Orta Çağ doğu tıbbının da sayesinde ilerleme kaydettiği gözlemlenebilmektedir.

Antik Dönem'de ayrıcalıklı olarak metodistler tarafından oldukça fazla önem verilen nekahet döneminin Hacı Paşa tarafından da iyileşmenin bir parçası olarak görülüp, değer verildiği anlaşılmaktadır. Müntahab-ı Şifáda, tıbbın pratiği kapsamında ele alınan ve meşakkatli bir süreç olan nekahet dönemini hastanın sorunsuz bir şekilde atlatabilmesi için Hacı Paşa'nın hiçbir ayrıntıyı atlamadığı, tavsiyeleri vasıtasıyla izlenebilmektedir. 


\section{KAYNAKLAR}

Aretaeus (1856). The Extant Works of Aretaeus, the Cappadocian, trans. Francis Adams, London: Sydenham Society.

Bayat, Ali H. (2016). Tip Taribi, İstanbul: Merkezefendi Geleneksel Tip Derneği Yayınları-Zeytinburnu Belediyesi Yayınları.

Black, Sir Douglas (1980). "The Story of Nephrology", Journal of the Royal Society of Medicine, 73/7, s. 514-518.

Celsus (1831). A Translation of the Eight Books of Aul. Corn. Celsus on Medicine, trans. G. F. Collier, London: Simpkin and Marshal.

Claridge, R. T. (1849). Every Man His Own Doctor: The Cold Water, Tepid Water, and Friction-Cure, the Cure of Disease in Horses and Cattle, New York: John Wiley.

Cooper, John M. (2004). Knowledge, Nature and the Good: Essays on Ancient Philosophy, Princeton: Princeton University Press.

Crum, Earl Le V. (1932). "Diet in Ancient Medical Practice as Shown by Celsus in his De Medicina”, The Classical Weekly, XXV/21, s. 161-165.

Eliaçık, Muhittin (2010). "Sihhat u Maraz'da Ahlât-1 Erbaanın İşlenişi”, Mukaddime, sayı: 1, s. 125-141.

Fagan, Garrett G. (2002). Batbing in Public in the Roman World, Ann Arbor: The University of Michigan Press.

Foster, George M. (1994). Hippocrates' Latin American Legacy: Humoral Medicine in the New World, Amsterdam: Gordon and Breach.

Furley, David J. ve Wilkie, James S. (1984). Galen: On Respiration and the Arteries, Princeton: Princeton University Press.

Galen (1916). On the Natural Faculties, trans. A. J. Brock, Cambridge, Mass.: Harvard University.

Ghasemzadeh, Nima ve Zafari, A. Maziar (2011). "A Brief Journey into the History of the Arterial Pulse", Cardiology Research and Practice, vol. 1, s. 1-14.

Graham, John (2009). Shapers of Our Age, Denver, Colorado: The Copper Beech.

Hacı Paşa (Celalüddin Hızır) (1990). Müntahab-ı Şifâ, ed. Zafer Önler, Ankara: Türk Dil Kurumu. 
Herophilus (1989). The Art of Medicine in Early Alexandria, ed. Heinrich von Staden, Cambridge: Cambridge University Press.

Hippocrates (1849). The Genuine Works of Hippocrates, vol. I, trans. Francis Adams, London: Sydenham Society.

Hippocrates (1978). The Nature of Man, Hippocratic Writings, trans. J. Chadwick and W.N. Mann, Harmondsworth: Penguin.

Hippokrates (2016). Aforizmalar, (çev. Eyüp Çorakl1), İstanbul: Türkiye İş Bankası Kültür Yayınları.

Jackson, Ralph (1990). "Waters and Spas in the Classical World", Medical History of Waters and Spas, ed. Roy Porter, London: The Wellcome Institute for the History of Medicine, s. 1-12.

Jackson, Ralph (1999). Roma İmparatorluğu'nda Doktorlar ve Hastalıklar, çev. Şenol Mumcu, İstanbul: Homer Kitabevi.

Kaya Gözlü, Emel (2009). "Muhyiddin Mehî’nin Müfîd (Nazmü’t-Teshil) Adlı Eserinin Türk Dili ve Tıp Tarihindeki Yeri ve Önemi”, Türkiyat Araștırmaları Dergisi, sayı: 20, s. 119-136.

Kouba, Erik-Wallen, Eric M. ve Pruthi, Raj S. (2007). "Uroscopy by Hippocrates and Theophilus: Prognosis Versus Diagnosis", The Journal of Urology, 177/1, s. 50-52.

Lewis, Orly (2017). Praxagoras of Cos on Arteries, Pulse and Pneuma: Fragments and Interpretation, Leiden and Boston: Brill.

Luke, Thomas D. ve Forbes, Norman H. (1913). Natural Therapy: A Manual of Physiotherapeutics and Climatology, Bristol: John Wright and Sons.

Marketos, S. G.- Eftychiadis, A. G. ve Diamandopoulos, A. (1993). "Acute Renal Failure According to Ancient Greek and Byzantine Medical Writers", Journal of the Royal Society of Medicine, vol. 86, s. 290-293.

Mattern, Susan P. (2008). Galen and the Rhetoric of Healing, Baltimore: Johns Hophinks University Press.

Nutton, Vivian (2013). Ancient Medicine, London and New York: Routledge. Önler, Zafer (1985). "Eski Anadolu Türkçesi Döneminde Yazılmış İki Tıp Kitabında Yer Alan Sağlık Bilgisi Terimleri”, Türk Dili Araștırmaları Yıllı̆̆r Belleten, s. 87-130. 
Paulus Aegineta (1844). The Seven Books of Paulus Aegineta: Translated from the Greek, vol. I, trans. Francis Adams, London: Sydenham Society.

Pearce, John M. S. (2013). “The Neuroanatomy of Herophilus”, JM European Neurology, 69/5, s. 292-295.

Phillips, E. D. (1973). Greek Medicine (Aspects of Greek and Roman life), London: Thames \& Hudson.

Plinius (G. Plinius Secundus) (1847-1848). Pliny's Natural History, In ThirtySeven Books, vol. I, trans. Philemon Holland, London: George Barclay.

Prichard, James C. (1847)."Temperament”, The Cyclopaedia of Practical Medicine, vol. IV, eds. John Forbes, Alexander Tweedie and John Conolly, Philadelphia: Lea and Blanchard, s. 349-363.

Prioreschi, Plinio (2001). A History of Medicine: Roman Medicine, vol. III, Omaha: Horatius Press.

Rhydding, Ben (1872). "As a Hygienic and Hydrotherapeutic Establishment", Edinburgh Medical Journal, XVII/ IX, s. 760-763.

Rosenfeld, Louis (1996). Four Centuries of Clinical Chemistry, New York and London: Routledge.

Rufus of Ephesus (2008). On Melancholy, ed. Peter E. Pormann, Tübingen: Mohr Siebeck.

Shew, Joel,(1849). Hydropathy or the Water Cure: Its Principles Processes and Modes of Treatment, New York: Fowlers and Wells.

Singer, A. Charles (1928). Short History of Medicine, Oxford: Clarendon Press.

Soranus of Ephesus (1956). Gynaecology, trans. Owsei Temkin, Baltimore: Johns Hopkins University Press.

Śródka, Andrzej (2003). “The Short History of Gastroenterology”, Journal of Physiology and Pharmacology, 54/3, s. 9-2.

Stillé, Alfred (1874). Therapeutics and Materia Medica, vol. I, Philadelphia: Henry C. Lea.

Thomson, George (1998). Eski Yunan Toplumu Üzerine İncelemeler: İlk Filozoflar, çev. Mehmet H. Doğan, İstanbul: Payel Yayınları.

Tipton, Charles M. (2003). Exercise Physiology: People and Ideas, New York: Oxford University Press. 
Üstün, Çă̆atay (2004). “Galen and His Anatomic Eponym: Vein of Galen”, Clinical Anatomy, say1: 17, s. 454-457.

Vitruvius (1826). The Architecture of Marcus Vitruvius Pollio, In Ten Books, trans. Joseph Gwilt, London: Priestley and Weale.

Whorton, James C. (2000). Inner Hygiene: Constipation and the Pursuit of Health in Modern Society, New York: Oxford University Press.

Yegül, Fikret (2006). Antik Çağ'da Hamamlar ve Yıkanma, İstanbul: Homer Kitabevi. 